\title{
Auditing audits: the method of Oxfordshire Medical Audit Advisory Group
}

John Derry, Martin Lawrence, Kay Griew, Julie Anderson, John Humphreys, K S Pandher

Abstract

Objectives-To develop a systematic method for both summative and formative audit of practice audits, and to use the method to review Oxfordshire practice audits and to plan improvement.

Design-Development of a coding system for the audit cycle subsequently used prospectively to assess audits reported to medical audit advisory group coordinators on practice visits.

Setting-All 85 general practices in Oxfordshire, of which 80 were visited by Oxfordshire Medical Audit Advisory Group coordinators.

Main outcome measures-Satisfaction of criteria for different levels of audit (full, partial, potential, planning or no audit) according to coding scores for practice audits.

Results-46 (58\%) practices were classified as doing audit, the remainder doing no audit or only collecting data for family health services authority returns. Of audits being undertaken, 55/102 (54\%) included planning care or the setting of targets.

Conclusions-The coding system offers the prospect of formative assessment for practices to help them improve their audits, and summative assessment for the family health services authority to satisfy the needs for professional accountability. Its use in Oxfordshire disclosed considerable deficiencies in the process of practice audit.

Implications and action-Practices in Oxfordshire should improve their audits. The advisory groups target to March 1992 is for $\mathbf{5 0 \%}$ of practices to be doing full or partial and $25 \%$ potential audit and half of the remainder planning audit. Practices are encouraged to include in their audit implementing change, planning care, and agreeing criteria for further assessment.

There is a paradox in the health circular HC(FP)(90) 8 for the setting up of medical audit

Oxfordshire Medical Audit Advisory Group,

Department of Public

Health and Primary Care,

Gibson Building, Radcliffe Infirmary, Oxford

OX2 6HE

John Derry, MRCGP, audit coordinator

Martin Lawrence, FRCGP, chairman

Kay Griew, MA, information officer

Julie Anderson, MRCGP, audit coordinator

John Humphreys, MRCGP, audit coordinator

K S Pandher, MRCGP, audit coordinator

Correspondence to:

Dr Lawrence.

BMF 1991;303:1247-9 the proper operation of their medical audit systems," and on the other the groups are accountable for "procedures to ensure that reports are cast in such a form that individual patients and doctors cannot be identified." "Proper operation" must include action to remedy problems identified by audit, but medical audit advisory groups are bound not to disclose to the family health services authorities the identities of doctors whose audits may be deficient. As it is important for the profession that medical audit remains professionally led and that problems are managed on an educational basis it will be incumbent on medical audit advisory groups to provide a summative assessment of audit in their areas sufficiently precise that government and managers in family health services authorities can be confident of the proper operation of medical audit.

Primary health care teams themselves need formative assessment of their audits. Medical audit is a new activity to many practices, and they tend to be

\section{Introduction}

concerned with the content of the audit in so far as it provides evidence of quality of care but less concerned $\triangle$ whether the audit is effective in enabling the practice to improve. Practices would benefit from a tool for $\vec{\circ}$ assessing the audits themselves.

This combination of summative and formative $\vec{\omega}$ features is not peculiar to audit. It has become particularly prominent in education, especially under- $\frac{3}{3}$ graduate education. For too long the summative $\omega$ approach to examination has driven the curriculum, $\mathscr{\omega}$ and the result has been professional compliance with an ineffective process. ${ }^{2}$ The introduction of formative $\vec{N}$ assessment integrated with the summative process has been one of the bases on which new teaching has been $N$ developed..$^{23}$

The Oxfordshire Medical Audit Advisory Group, $\stackrel{\bigcirc}{\leftrightarrows}$ which began by advocating an audit cycle for use by $\vec{\sigma}$ practices, has decided to use the same cycle for $Z$ auditing audits. Indeed, this reflects the statement in the health circular that medical audit advisory groups "will need to include evaluation of the audit exercise itself in the arrangements made for audit." By approaching this audit with the same rigour as is $\vec{\oplus}$ applied to medical audit we believe that we can offer.valuable summative audit for the family health services 0 authority and formative audit for practices.

We developed and advocate for use in Oxfordshire a cycle based on that described by the Royal College of Physicians (fig 1). ${ }^{4}$ The cycle was adapted in two $\mathbb{D}$ particular respects. Firstly, we thought it important to $\Rightarrow$ emphasise that the practice should choose the topic, because so many topics in primary care have recently been imposed and, especially, because ownership of the topic is so important in ensuring enthusiasm for conducting the audit and for acting on the results. Secondly, we thought it necessary to clarify the term "setting standards," which is commonly used but open to varied interpretations. Who sets the standards, for whom, and are they minimum, average, or ideal? For $\mathrm{O}$ this reason we tried to be more precise. Elements of care that are important, measurable, and changeable $\stackrel{\circ}{3}$ may be called indicators. The clearest way to examine $N$ an indicator is to define it so precisely that it is possible 
to say whether it is present or not. (For instance, diastolic blood pressure is a good indicator of blood pressure control, but by asking, "Is diastolic blood pressure $<95 \mathrm{~mm} \mathrm{Hg}$ ?" a yes/no answer is possible.) Such a measure may be called a criterion. Once a criterion is chosen then a practice can measure its level of performance in attaining that criterion-for example, $60 \%$ of treated hypertensive patients have a diastolic blood pressure of $<95 \mathrm{~mm} \mathrm{Hg}$ - and it can se its own target standards - for example, $80 \%$ of treated hypertensive patients should have a diastolic blood pressure of $<95 \mathrm{~mm} \mathrm{Hg}$.

\begin{tabular}{|c|c|c|}
\hline Code & Description & Activity \\
\hline I & Choose topic & \\
\hline II & Set target standards & $\begin{array}{l}\text { Criteria identified against which a level of performance } \\
\text { can be measured }\end{array}$ \\
\hline III & Observe practice & Data collected, analysed, and presented \\
\hline IV & $\begin{array}{l}\text { Compare performance } \\
\text { with targets }\end{array}$ & $\begin{array}{l}\text { Discussions among doctors (IVd) or including other } \\
\text { team members (IVt) }\end{array}$ \\
\hline $\mathrm{V}$ & Implement change & Changes made as a result of discussions \\
\hline & Plan care & Written plans for future management \\
\hline VI & Cycle repeated & $\begin{array}{l}\text { Repeated once }(\mathrm{VI}) \text { or regularly as part of a practice } \\
\text { programme (VIr) }\end{array}$ \\
\hline
\end{tabular}

BOx 1-Coding stages of audit cycle

\section{Methods}

Criteria for assessment-To enable the group to set target standards or evaluate performance, criteria were needed against which to assess an audit. To define these criteria precisely we first coded the various stages of the audit cycle (box 1). We then defined different levels of audit according to the codes achieved (box 2).
Criterion
Full audit
Criterion satisfied if:
Partial audit
Five of six codes present
Codes I and III present, plus either II or $\mathrm{V}$
Potential audit Codes I and III present
Planning audit Topic chosen and definite intentions for audit
No audit

Box 2-Criteria for different levels of audit

Observing practice - We entered the audit cycle at the point of observing practice because, with no prior information, we could not set targets. Four audit coordinators (general practitioners each with two sessions a week) were appointed, each with responsibility for about 20 practices. Over six months from January to June 1991 they endeavoured to visit every practice in Oxfordshire, succeeding in meeting with 80 of the 85 . Of the remainder, two are resistant and three are having some difficulty in scheduling a meeting. The first meeting was with as many partners and team members as possible, at which a "key contact" was identified and authorised by the partners for future contacts. Information about the practice and its past and current audit activities was collected with a semistructured profile. The coding of each practice's audits was carried out by individual coordinators according to the agreed schedule but without measurement of repeatability.

\section{Results}

The group's information officer analysed the data at two levels. Firstly, audits were analysed for each practice so that the members of the primary health care team could see which of their audits included the various stages of the audit cycle (box 3). Secondly, the audits of all Oxfordshire practices visited were analysed to give a measure of audit activity in the county (table). As an analysis of all current audits conceals the fact that some practices do many audits and others few or none each practice's best audit was also determined. The table also shows the results both for practices' best current audit and for the best audit they had ever done.

\section{Discussion}

It is currently fashionable to extol the virtues of audits of outcome and decry audits of process. In the case of auditing audits the situation is not so clear. In many cases results of audit are used to show differences among practices and then review the implications of such variation. ${ }^{67}$ The outcome of audit in producing change over time is also frequently reported..$^{8-11}$ On the other hand, there is little reported evidence relating to the audit of the process of audit, yet there is increasing evidence that failure to complete all stages in the process of audit has a serious effect on its outcome. That is, audit which fails to include planning and the setting of targets is less likely to lead to change and improvement..$^{12}$

Auditing the process of audits in Oxfordshire disclosed surprising numbers of practices not undertaking audits and of audits omitting steps essential for effectiveness in inducing change. Almost a third of practices were classed as doing no audit in a district where $97 \%$ of practices attain the targets for both immunisation and cytological screening. The classification system demands "choosing the topic" as a requirement for satisfying any of the criteria of audit; results for immunisation, cytological screening, referrals, and prescribing analysis and cost activity (PACT) were regarded as only collecting data and not audit unless the practice chose to go beyond the requirements of the family health services authority and evaluate its data and plan care.

Notably three quarters of practices had done some audit previously but only $46(58 \%)$ are doing so now. Of course the level of audit activity currently must be less than that historically (because it is a subset), but the reduction in audit was also attributed by the visiting coordinators to the pressure practices are experiencing to complete their data collection for the family health services authority (which satisfies only code III), which is squeezing out activity we term audit. Not only may the fall in the total number of audits be attributable to the new contract but the poor quality of audits may also be a result. Currently about a third of audits being undertaken are of categories I, III, and IV, which omit plans for care or targets for future assessment. Most of the information which practices must produce for annual reports, such as referral statistics or numbers of patients seen for health checks, entail producing only raw data. This does not encourage practices in the good habits of planning or evaluating, and the time involved in producing the data reduces that available for such planning. In the cases where targets have been imposed they have been inflexible and unrelated to local conditions or to improvement: again this is counter to the principle of practices setting targets.

There is hope. Increasingly, family health services authorities are expecting practices to offer protocols for and evaluation of health promotion clinics; practice reports will be evaluated and improvements suggested. Family health services authorities may eventually be given discretion to vary imposed targets to make them realistic or stimulating. External management will bring pressure to bear. But even more important for the profession is the prospect that performance will improve owing to professional education and that such improvement will be shown to the authorities by the accountability of medical audit advisory groups. Both 
these functions - the formative and the summativewill be enhanced by the use of a structured method of analysing practice audits.

The group itself needs to work according to audit principles; we are using our own cycle (introduction/ choosing the topic; methods/observing practice; discussion/evaluation of data). The group also needs to plan and set targets, and again formal evaluation of the audit cycle helps this process.

Planning-In Oxfordshire we have devised a three pronged approach. Firstly, to help practices with their own audits and with implementing small problem solving audits. Secondly, to develop district criteria for assessing major areas of care which many practices are reviewing, such as diabetes, preventive procedures, and access. Thirdly, to develop one or two "off the peg" audits with full guidelines for those who wish to do them or are trying to get started. In each case the quality of the audits performed will be assessed using the coding system.

Setting targets-Using the criteria for assessment (box 2) our aim is (a) to encourage practices to set themselves the target that every audit will include code $\mathrm{V}$ (implementing change and planning care) and, when possible, code II (agreeing criteria for further assessment) and (b) to achieve the following levels of audit in Oxfordshire by March 1992: 50\% of practices doing

Analysis of audits in 80 practices in Oxfordshire. Figures are numbers (percentages)

\begin{tabular}{lcccccc}
\hline & \multicolumn{7}{c}{ Level of audit } \\
\cline { 2 - 7 } & Full & Partial & Potential & Planning & None & Total \\
\hline All current audits & $39(38)$ & $16(16)$ & $29(28)$ & $18(18)$ & $\begin{array}{c}\text { Not } \\
\text { applicable }\end{array}$ & 102 \\
Practices' best current audit & $25(31)$ & $7(9)$ & $14(17)$ & $6(8)$ & $28(35)$ & 80 \\
Practices' best ever audit & $32(40)$ & $17(21)$ & $11(14)$ & $3(4)$ & $17(21)$ & 80 \\
\hline
\end{tabular}

full or partial audit; $25 \%$ of practices doing potential audit; and half of the remainder planning audit.

In conclusion, the development of a coding system for the audit cycle and the definition of criteria for the completeness of audits enabled the medical audit advisory group to set target standards for its activity. We believe that this goes some way to resolving the paradox described in the introduction. We can also use the same system in helping individual practices to improve the completeness of their audits.

1 Department of Health. Medical audit in the family practitioner services. London $\mathrm{DoH}, 1990$. (Health circular $\mathrm{HC}(\mathrm{FP})(90) 8$.

2 Association of University Teachers in General Practice, United Kingdom, and Northern Ireland. Undergraduate medical education in general practice. London: Royal College of General Practitioners, 1984. (Occasional paper No 28.)

3 Jewell D. Learning through examinations: use of an objective structured clinical examination as a teaching method in general practice. Fournal of the Royal College of General Practitioners 1988:38:506-8.

4 Royal College of Physicians. Medical audit: a first report. London: RCP, 1989.

5 Donabedian A. Introduction. Explorations in quality assessment and monitoring. Vol ii. The criteria and standards of quality. Ann Arbor: Health Administration Press, 1982 .

6 Wilson A. Cervical cytology in the Vale of Trent faculty of the Royal College of General Practitioners, 1985-8. BMF 1990;300:376-8.

7 Crombie DL, Fleming DM. Practice activity analysis. London: Royal Colleg of General Practitioners, 1988. (Occasional paper No 41.)

8 Fleming DM, Lawrence MSTA. Impact of audit on preventive measures $B M \mathcal{A} 1983 ; 287: 1852-4$.

9 Baker R. Problem solving with audit in general practice. BMF 1990;300: 378-80.

10 Marsh GN, Channing DM. Narrowing the gap between a deprived and an endowed community. BMF 1988;296:173-6.

11 Needham A, Brown M, Freebourne S. Introduction and audit of a general practice antibiotic formulary. Fournal of the Roval College of General Practitioners 1988;38:166-7.

12 Grol R, Mokkink H, Schellevis F. The effects of peer review in genera practice. Fournal of the Royal College of General Practitioners 1988;38:10-3.

3 Centre for Health Services Research, Newcastle upon Tyne. North of England study of standards and performance in general practice. Volume III The effects of standard setting and implementing clinical standards. Newcaste upon Tyne: CHSR, 1991.

International Quality Assurance

\title{
Medical audit: the Spanish experience
}

\author{
Rosa Suñol, R Delgado, A Esteban
}

The population of Spain is 37.6 million with a high urban population. In 1985 general mortality was $8.0 \%$, among the lowest in Europe, infant mortality was $8 \cdot 5 / 1000$ live births, and life expectancy at birth was 72.5 years for males and 78.6 for females. ${ }^{1}$ Spain has a mixed public and private health care system, in which the public side predominates. On average $69 \%$ of hospital beds are in the public sector. Until 1986 the health system was based on a national health insurance system covering $95 \%$ of the population and supported by contributions from employers and employees. Management services was centralised through an institute called INSALUD. The health insurance system owned hospitals and ambulatory care facilities and also had contract services with other public and private hospitals. Since 1979 the total number of hospital beds (4.8/1000 population) has not increased, and the pattern of morbidity among hospital patients resembles that in other developed countries.

Public sector hospitals are organised into five sections with the same level of responsibility (medical, nursing, administration, hotel services, and staff) and are headed by a general manager, who may or may not be a physician. Physicians are represented professionally by the medical colleges, and specialist associations (for example, surgeons, internists, etc) also play an important part in medical opinion.
The Health Act of 1986 established a universal, decentralised, public health care system based on a national health service to provide integrated health services for the whole population; since then has begun the process of transforming the previous system into the new national health service. The new health service has a higher proportion of general tax revenue ${ }^{2}$ and represents an important change to the previous system in that full management power is being transferred to autonomous communities. This process started in 1981 , and at present $57 \%$ of the population is cared for under transferred management. Also, primary health care will be the basis of the new system and ambulatory care facilities are being converted into new primary health care centres which are better staffed and more oriented towards prevention and the community. Such changes are not always easy to carry out because previous organisational systems coexist with new developments. After a parliamentary request an independent committee was formed to determine the changes necessary in organisation.

\section{External audit: accreditation systems}

The first accreditation system in Spain was developed in Catalonia in 1981, a region with a high proportion of private beds. Developed by the autono- 